\title{
Avaliação química e ambiental de misturas asfálticas rejuvenescidas
}

\section{Chemical and environmental assessment of rejuvenated asphalt mixtures}

João Paulo Souza Silva ${ }^{1}$, Márcio Muniz de Farias ${ }^{2}$

\author{
${ }^{1}$ Departamento de Engenharia de Transportes - Universidade Federal de Goiás - UFG CEP: 74968-755, Rua Mucuri, \\ Bairro Conde dos Arcos - Aparecida de Goiânia, GO, Brasil. \\ e-mail: jpss@ufg.br \\ ${ }^{2}$ Programa de Pós-graduação em Geotecnia - Universidade de Brasília - UnB, Brasília, Distrito Federal, Brasil. \\ e-mail: muniz@unb.br
}

\section{RESUMO}

A reciclagem é um tema que vem ganhando bastante espaço em diversas áreas da engenharia. Quando se reaproveita um material em obras civis, indiretamente se está contribuindo para a preservação da natureza. Dentro deste contexto, a reciclagem de revestimentos asfálticos é um assunto que desperta grande interesse, mas que requer estudos mais aprofundados. Desta forma, o presente trabalho tem como objetivo estudar os efeitos de produtos rejuvenescedores no comportamento de ligante asfáltico envelhecido, visando sua aplicação em reciclagem de revestimentos de pavimentos rodoviários. Para tanto, inicialmente foi extraído ligante residual e em seguida foram adicionados rejuvenescedores a base de alcatrão (RejuvaSeal) e outros a base de óleo de xisto, conhecidos comercialmente com AR-5, AR-250 e AR-500, nas taxas de 15, 20 e 25\%, de modo a verificar qual teor seria apropriado para recuperar as características originais do ligante. Entre as diversas conclusões obtidas neste trabalho tem-se que a mistura contendo $20 \%$ de AR-5 apresenta o melhor comportamento quando comparada a um ligante asfáltico novo (CAP 50-70). As análises químicas e ambientais mostraram que a reciclagem de material fresado de revestimento asfáltico utilizando rejuvenescedor é uma solução tecnicamente possível e ambientalmente correta para pavimentação.

Palavras-chave: ligantes asfálticos rejuvenescidos, análise química, análise ambiental

\section{ABSTRACT}

Recycling is a topic that has been gaining enough space in various areas of engineering. When reuses material in civil works, indirectly it is contributing to the preservation of nature. Within this context, the recycling of asphalt coatings is a subject that arouses great interest, but that requires further study. Thus, this paper aims to study the effects of rejuvenating products on aged asphalt binder behavior, for their application in recycling road surface coatings. Therefore, it was initially extracted residual binder and then were added rejuvenating tar base (RejuvaSeal) and other shale oil based commercially known AR-5, AR-250 and AR-500, at rates of 15, 20 and $25 \%$, in order to see which content would be appropriate to recover the original characteristics of the binder. Among the many findings from this study is that the mixture containing $20 \%$ of AR-5 shows better behavior when compared to a new asphalt binder (CAP 50-70). The chemical and environmental analysis showed that the recycling of material milled using rejuvenating asphalt layer is a technically feasible solution for flooring and environmentally friendly.

Keywords: asphaltic binders rejuvenating, chemical analysis, environmental analysis.

\section{INTRODUÇÃO}

O Brasil é um país de dimensões continentais, somando mais de 207 milhões de habitantes distribuídos irregularmente sobre cerca de 8,5 milhões de $\mathrm{km}^{2}$,[1] dotado de uma malha rodoviária pavimentada relativamente pequena em relação à malha total, por vezes em mal estado de conservação, com poucas ferrovias e uma rede fluvial de baixa utilização [2].

A chegada da indústria automobilística nas décadas de 50 e 60 e a política de desenvolvimento adota- 
da estabeleceram o modal rodoviário como prioritário para o país. Sendo assim, os investimentos em infraestrutura de transportes no Brasil têm sido historicamente maiores em rodovias por possibilitarem uma maior flexibilidade no transporte de cargas e passageiros, e hoje este modal é responsável por mais de $90 \%$ do transporte de passageiros e $61 \%$ do transporte de cargas [2].

Atualmente, no Brasil a extensão total da malha rodoviária incluindo a esfera Federal, Estadual e Municipal está em torno de 1,73 milhão de quilômetros, sendo apenas 12,3\% pavimentados. Os investimentos na área de transportes rodoviários no ano de 2015 foram de 5,95 bilhão de reais [2].

A deterioração verificada nos pavimentos brasileiros é em grande parte causada pelo excesso de carga por eixo dos veículos transportadores e pela falta de manutenção das rodovias, aliada às intempéries. Estes mecanismos causam rompimento da camada de revestimento provocando assim grande desconforto e prejuízo ao usuário.

O meio técnico rodoviário tem se esforçado para buscar novas tecnologias e desenvolver soluções mais econômicas de restauração dos pavimentos, muitos já bastante deteriorados. Entre as novas metodologias estudadas, destaca-se a reciclagem dos revestimentos asfálticos, que além de apresentar rapidez executiva e custos competitivos, preza pelo aspecto ambiental [3].

A reciclagem de misturas asfálticas vem sendo executada no Brasil desde meados da década de 1980, principalmente após a introdução de máquinas fresadoras no país. Este tipo de reciclagem reaproveita o material fresado da capa asfáltica, posteriormente utilizado com revestimento ou binder a partir da incorporação de agentes rejuvenescedores que recuperam as características do ligante original envelhecido, apesar que também existem condições de uso do fresado sem incorporação de aditivos químicos[4].

O envelhecimento do ligante em misturas asfálticas ocorre devido ao efeito da temperatura, do ar, da luz solar, da chuva e do tempo, que resulta em um aumento da consistência do asfalto e em maior rigidez da camada betuminosa. Este "endurecimento" do ligante asfáltico, combinado com a ação do tráfego, acarreta o aparecimento de fissuras e degradação acelerada no pavimento [3].

Essas misturas asfálticas envelhecidas, entretanto, podem ser recuperadas por meio da incorporação de aditivos químicos, chamados agentes rejuvenescedores, que têm como finalidade repor os compostos aromáticos e resinas para que as propriedades originais do ligante sejam restabelecidas.

Diante deste fato e devido à escassez de pesquisas nacionais referentes ao assunto, este trabalho foi idealizado e desenvolvido na tentativa de se obter o domínio das condições de aplicação de agentes rejuvenescedores em materiais fresados, além de em materiais envelhecidos in situ, por meio de ensaios químicos e ambientais preconizados na literatura e normas técnicas vigentes. A partir daí, potencializa-se a reciclagem de toneladas de materiais de revestimentos asfálticos deteriorados, que podem ser empregados na pavimentação de dezenas de quilômetros em estradas no país.

\section{REFERENCIAL TEÓRICO}

\subsection{Rejuvenescimento de misturas asfálticas}

Devido ao efeito da temperatura, oxigênio, luz solar, chuva e tempo, o ligante asfáltico tem sua consistência aumentada, promovendo o envelhecimento, ou seja, uma maior rigidez da camada betuminosa. $\mathrm{O}$ concreto asfáltico ao envelhecer sofre aumento relativo no teor de asfalteno e diminuição no teor de resinas e óleos aromáticos [4].

Assim, para recuperar as propriedades originais do CAP, principalmente quando se trabalha coma reutilização de misturas asfálticas envelhecidas, utiliza-se uma técnica que visa à reutilização dos agregados e do aglutinante (ligante) do revestimento envelhecido. Para tal é necessária a incorporação de aditivos químicos ao material envelhecido, os chamados agentes rejuvenescedores, que reduzem a viscosidade e repõem as resinas e os compostos aromáticos para que as propriedades originais do ligante sejam restabelecidas [3].

Os rejuvenescedores à base de óleo de xisto e à base de alcatrão são os principais produtos disponíveis atualmente no mercado para esta finalidade. Um dos agentes rejuvenescedores é fornecido pela empresa brasileira de petróleo (Petrobrás). Este produto, à base de óleo de xisto, é dividido em duas categorias (a quente e a frio), e regido pelo regulamento técnico DNC 04/97 portaria n ${ }^{\circ} 44$ de 29/09/1997[6].

Os agentes a quente são denominados "Aditivos Asfálticos de Reciclagem para Misturas a Quente" (AR) e os a frio recebem o nome de "Agentes de Reciclagem Emulsionados" (ARE). Cada um deles apresenta seis tipos em função da viscosidade do ligante. Outro agente rejuvenescedor encontrado no mercado brasileiro é o produto a base de alcatrão que foi desenvolvido pela empresa americana PRI (Pavement Rejuvenation International), conhecido comercialmente pelo nome de RejuvaSeal ${ }^{\circledR}$, este é comercializado no mercado 
nacional pela empresa SPM que se associou à empresa americana.

\subsection{Agentes rejuvenescedores a quente (AR)}

O AR é utilizado na recomposição da consistência original do ligante asfáltico presente no revestimento que está sendo reciclado, pois contém compostos aromáticos que visam devolver ao asfalto a característica original de ductilidade e consistência (propriedades reológicas) perdidas pelo envelhecimento ao longo do tempo de serviço do pavimento. Os ARs são asfaltos de baixa consistência, usados em serviços de reciclagem a quente.

A seleção do tipo de $\mathrm{AR}$ a ser empregado no serviço de reciclagem dependerá das características de envelhecimento do ligante presente no revestimento a ser reciclado. Quanto mais envelhecido estiver o ligante asfáltico residual (medido em termos de penetração ou viscosidade) menos consistente deverá ser o AR a ser usado.

Geralmente obtêm-se valores inadequados da viscosidade do asfalto recuperado, devido a problemas de contaminação pelo solvente utilizado na recuperação do ligante extraído do revestimento asfáltico fresado, influenciando a determinação do teor de AR necessário para rejuvenescer adequadamente do ligante asfáltico envelhecido. O tempo de mistura do AR com outros componentes da mistura também ocasiona perda na eficiência do AR no restabelecimento das propriedades reológicas do asfalto envelhecido, deixando o ligante com viscosidade elevada, influenciando a rigidez final da mistura asfáltica [7].

Os agentes rejuvenescedores a quente, ARs, especificados pelo regulamento técnico DNC $\mathrm{n}^{\circ} 04 / 97-$ Portaria n 44 de 29/09/1997[6] são: AR-1, AR-5, AR-25, AR-75, AR-250, AR-500. A escala de concentração de óleo de xisto é composta por AR-1 (maior concentração) e AR-500 (menor concentração). As especificações dos três principais AR's são apresentadas na Tabela 1.

Tabela 1: Especificação de rejuvenescedores AR (DNC)

\begin{tabular}{|c|c|c|c|c|c|c|}
\hline \multirow{2}{*}{ CARACTERÍSTICAS } & \multirow{2}{*}{ UNID. } & \multicolumn{3}{|c|}{ ESPECIFICAÇÕES } & \multicolumn{2}{|c|}{ MÉTODOS } \\
\hline & & AR-5 & AR-250 & AR-500 & ABNT & ASTM \\
\hline \multirow[b]{2}{*}{ Viscosidade Cinemática a $60^{\circ} \mathrm{C}$} & \multirow[b]{2}{*}{$\mathrm{cSt}$} & Mín-Máx & Mín-Máx & Mín-Máx & \multirow[b]{2}{*}{14756} & \multirow[b]{2}{*}{ D2170 } \\
\hline & & $176-900$ & $\begin{array}{l}12501- \\
37500\end{array}$ & $\begin{array}{c}37501- \\
60000\end{array}$ & & \\
\hline Ponto de Fulgor VAC & ${ }^{\circ} \mathrm{C}$ & 218 & 218 & 218 & 11341 & D 92 \\
\hline Teor de Saturados Massa & $\%$ & 30 & 30 & 30 & ----- & D2007 \\
\hline \multicolumn{7}{|c|}{ Efeito do Calor e do $\mathrm{Ar}$ a $163^{\circ} \mathrm{C}$ (RTFOT ou TFOT) } \\
\hline Razão de Viscosidade & $\%$ & 4 & 4 & 4 & \multirow{2}{*}{$\begin{array}{c}15235 \\
\text { ou } \\
14736\end{array}$} & \multirow{2}{*}{$\begin{array}{r}\text { D2872 } \\
\text { ou } \mathrm{D} 754\end{array}$} \\
\hline Variação de Massa & $\%$ & 4 & 3 & 3 & & \\
\hline Densidade $20 / 4^{\circ} \mathrm{C}$ & ------ & anotar & anotar & anotar & 6296 & D 70 \\
\hline
\end{tabular}

VAC: Ponto de Fulgor Vaso Aberto Cleveland

Razão de Viscosidade: Viscosidade a $60^{\circ} \mathrm{C}$ após RTFOT / Viscosidade a $60^{\circ} \mathrm{C}$ antes RTFOT

\subsection{Agente rejuvenescedor a base de alcatrão}

Pouco depois da Primeira Guerra Mundial, os engenheiros do Exército Americano, iniciaram uma grande pesquisa para desenvolver uma substância a partir de derivados de petróleo no intuito de melhorar a manutenção de pisos asfálticos.

A década de 1970 foi um período importante para o desenvolvimento de rejuvenescedores à base de alcatrão com o lançamento de um relatório intitulado "Rejuvenescimento de pavimento asfáltico", mostrando uma significativa melhoria na viscosidade dos ligantes asfálticos testados [8]. Em 1976, um estudo realizado por engenheiros americanos indicou que o uso de rejuvenescedores a base de alcatrão (RejuvaSeal@) prolonga a vida útil do pavimento asfáltico.

No final dos anos 1980, os produtos rejuvenescedores foram recomendados pela FAA (Federal Aviation Administration) para o uso em aeroportos. Atualmente o RejuvaSeal® é usado em boa parte do mundo 
na conservação de auto-estradas, pistas de aeroportos, pátios e portos. Foram realizados vários testes que confirmam que o RejuvaSeal ${ }^{\circledR}$ representa uma alternativa de custo-benefício maior quando comparado com métodos antigos de reconstrução [9].

O "RejuvaSeal" é um tratamento à base de alcatrão para pavimento asfáltico, proveniente de uma mistura cuidadosa de diferentes materiais e possui duas funções principais: restaurar e proteger o pavimento asfáltico envelhecido. A Tabela 2 mostra a composição do agente rejuvenescedor à base de alcatrão[10].

Tabela 2: Composição do RejuvaSeal

\begin{tabular}{c|c}
\hline Alcatrão & $35 \%-50 \%$ \\
\hline Destilado de Petróleo & $32 \%-42 \%$ \\
\hline Rejuvenescedor & $15 \%-40 \%$ \\
\hline
\end{tabular}
pas[10]:

As principais ações destes produtos rejuvenescedores à base de alcatrão são divididas em duas eta-

- Reduzir a taxa de envelhecimento do ligante, por meio da selagem e proteção da superfície do pavimento asfáltico, agindo como camada impermeabilizante, resistente à ação da água e de combustíveis;

- Estender a vida de uso do pavimento, por meio do rejuvenescimento do ligante asfáltico nas camadas superficiais do revestimento, penetrando nos vazios da mistura e reconstituindo as propriedades de viscosidade e ductilidade do ligante oxidado.

Embora o produto não altere a estrutura do pavimento, o RejuvaSeal supostamente penetra na superfície do pavimento, revitaliza o ligante asfáltico e sela a superfície contra contaminantes, como água, combustível e outros produtos químicos [10].

O RejuvaSeal@ é um produto à base alcatrão destilado de carvão, o qual é utilizado como banho selante e rejuvenescedor em camadas de revestimento asfáltico de aeroportos e rodovias. Em pesquisa realizada por Fwa [8], foi observado o comportamento mecânico de corpos de prova revestidos com "RejuvaSeal" submetidos ao ataque de combustíveis, como gasolina e óleo diesel. Como resultado, quando comparados com corpos de prova que não receberam o tratamento selante, verificou-se uma redução da perda de estabilidade Marshall de 50 a 80\%, uma redução na perda de Resistência à Tração por compressão diametral de 10 a $30 \%$, além de uma redução na perda de Módulo de Resiliência de 50 a 80\%. Esta significativa redução na perda da resistência mecânica após ataque químico sugere que o revestimento proporcionado pelo rejuvenescedor reduz significativamente o efeito nocivo dos combustíveis na mistura asfáltica.

No Brasil uma pesquisa realizada por Silva et al. [11], mostra que corpos de prova revestidos com RejuvaSeal@ e submetidos às ações de imersão em água, gasolina, e a combinação destes, apresentaram uma menor perda de resistência à tração e de módulo de resiliência do que as amostras correspondentes sem revestimento. Os resultados dos testes e avaliações estatísticas para a combinação água+gasolina apresentou o maior potencial agressor, seguido da gasolina e por fim o efeito isolado da água.

\section{MATERIAIS E MÉTODOS}

Quatro rejuvenescedores foram utilizados na pesquisa, sendo três à base óleo de xisto e um à base de alcatrão. Os agentes rejuvenescedores à base de óleo de xisto são produzidos pela Petrobrás e foram adquiridos junto à distribuidora Betunel Indústria e Comércio Ltda, com sede na cidade do Rio de Janeiro-RJ. Os tipos utilizados nesta pesquisa são: AR-5, AR-250 e AR-500, escolhidos de modo a representar as consistências mínima e máxima disponíveis no mercado brasileiro e um ligante com consistência intermediária.

O rejuvenescedor à base de alcatrão não é um produto nacional e é conhecido comercialmente com o nome de RejuvaSeal® e foi adquirido junto ao Grupo SPM, sediado em São Paulo-SP, sendo este grupo responsável pela importação e comercialização do produto no Brasil.

\subsection{Extração e caracterização do ligante presente no fresado}

Foram retiradas, logo após estocagem, amostras da pilha de material fresado que, posteriormente, foram encaminhadas ao laboratório para execução de ensaios de caracterização, tais como granulometria e percentagem de betume (método Rotarex).

Inicialmente, foi separado o ligante asfáltico envelhecido dos agregados utilizando processo de centri- 
fugação (equipamento Rotarex) e destilação pelo método do Rotavaporador.

O teor do asfalto no material fresado foi determinado conforme equação abaixo:

$$
T=\frac{M a-M d}{M a} x 100
$$

Onde: $\mathrm{Ma}=$ massa da amostra antes da extração e Md = massa da amostra após a extração.

O procedimento de extração consistiu em adicionar um solvente, neste caso o tricloroetileno, ao material fresado e colocá-lo dentro do equipamento Rotarex ,deixando o mesmo girar até que se complete a separação da solução (CAP envelhecido mais solvente), sendo medida sua massa para a determinação do teor de asfalto. Nesta etapa foi realizada também uma filtragem usando um funil de Buchner com filtro de papel de $28 \mu$ (micrometro) ,acoplado a um Kitasato ligado a uma bomba de vácuo, a fim de evitar a contaminação do CAP por material fino (filer) conforme mostra a Figura 1.

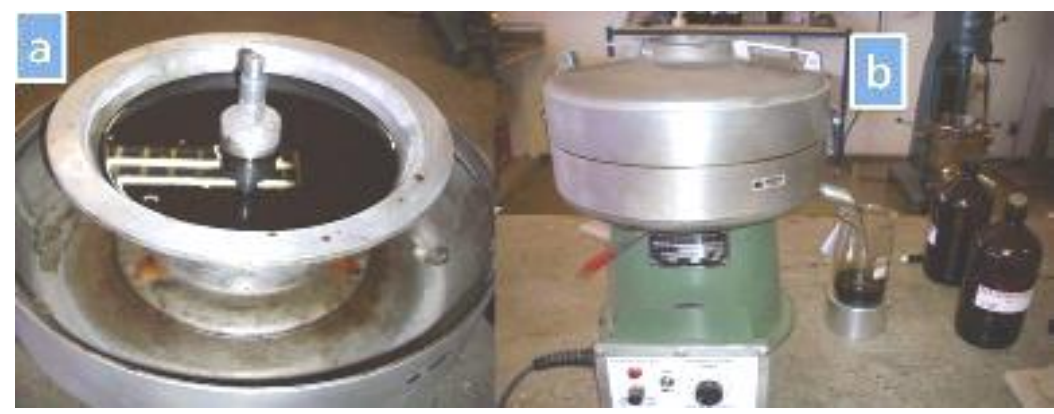

Figura 1: (a) Cuba do Rotarex com a mistura fresado-solvente (b) Equipamento Rotarex

Após separar o ligante dos agregados minerais e do material pulverulento, o mesmo foi levado ao destilador (Figura 2) a fim de fazer a separação entre o CAP envelhecido e o solvente (tricloroetileno).

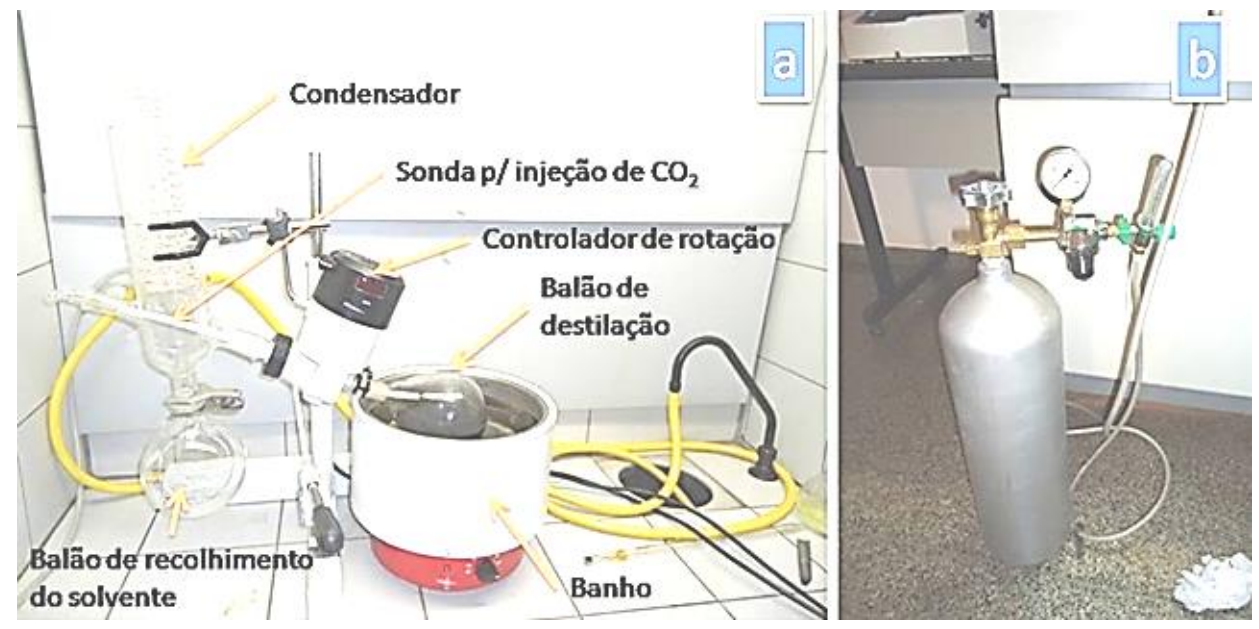

Figura 2: a) Equipamento Rotavaporador (b) Balão de CO2.

Neste processo foi utilizado o método Rotavaporador onde a solução de CAP mais tricloroetileno é colocada dentro de um balão de destilação que fica girando dentro de uma cuba com glicerina aquecida até fazer com que o tricloroetileno evapore. Neste balão foi ainda injetado um gás inerte (dióxido de carbono $\mathrm{CO} 2$ ), fazendo com que o vapor de tricloroetileno seja expulso para dentro de um condensador onde o mesmo é resfriado e precipitado em outro balão, restando no balão inicial apenas o CAP envelhecido. O uso de um gás inerte para a expulsão do vapor de tricloroetileno faz-se necessário a fim de evitar o aumento da oxidação do ligante envelhecido.

Os procedimentos acima citados estão em conformidade com a norma americana ASTM D 5404[12] (Recuperação de Asfalto da Solução usando o Equipamento Rotavaporador) salvo algumas adaptações como no caso do uso da glicerina no banho, pois quando se utiliza água como preconiza a norma, não é possível 
atingir a temperatura suficiente para que o solvente seja evaporado e condensado para sua posterior captação.

\subsection{Cromatografia (SARA)}

No processo de envelhecimento, tanto de curto prazo (usinagem manuseio e aplicação) quanto no de longo prazo (em serviço) ocorre normalmente uma diminuição do teor de óleos aromáticos, que se transformam em resina que por sua vez se transformam parte em asfaltenos, resultando ao final do processo numa pequena ou nenhuma variação do teor de saturados e resinas, diminuição do teor de aromáticos e aumento no teor de asfaltenos.

A cromatografia sobre coluna de sílica IATROSCAN é uma técnica que permite separar diretamente estes constituintes do ligante asfáltico em função de sua polaridade, obtendo-se assim as quatro famílias químicas SARA (saturados, aromáticos, resinas e asfaltenos) de Corbett $[3,13]$

A partir do teor de cada fração SARA pode-se monitorar a evolução da composição química do ligante asfáltico envelhecido após mistura com diferentes rejuvenescedores. Também foi determinado o Ic (Índice de Instabilidade Coloidal), que segundo Gaestel [14], é calculado conforme a Equação 2.

$$
I c=\frac{S+A}{R+A r} \quad \text { onde: } \mathrm{S}=\text { saturados, } \mathrm{A}=\text { asfaltenos; } \mathrm{R}=\text { resinas e } \mathrm{Ar}=\text { aromáticos, todos em \%. }
$$

\subsection{Espectrometria de Ressonância Magnética Nuclear - RMN}

A técnica de ressonância magnética nuclear (RMN) fundamenta-se na determinação de propriedades de uma substância por meio da correlação da energia absorvida contra a frequência em megahertz (MHz) do espectromagnético. Utilizam-se as transições em níveis de energia rotacionais do núcleo componente das espécies (átomos ou íons) contidas na amostra, ocorrendo necessariamente sob a influência de um campo magnético e concomitante sob irradiação de ondas de rádio na faixa de frequências $(\mathrm{MHz})$.

Recentemente a ressonância magnética nuclear (RMN) tornou-se um eficiente método para analisar produtos de petróleo, sendo que os espectros (comprimento de onda ou frequência) do CAP geralmente apresentam duas regiões de deslocamentos químicos distintos que correspondem às regiões de alifáticos e aromáticos, este último, mais difícil de analisar devido à grande superposição de picos.

Esta dificuldade é relatada por alguns autores como Shakirullah et al,[15], Jennings \& Pribani (1991) [16], que enfatizam esta dificuldade em analisar a região dos aromáticos em espectros de RMN de 1H e 13C dos ligantes asfálticos que se apresentam como uma mistura complexa de compostos orgânicos.

Esta técnica foi utilizada para avaliação das alterações estruturais que a mistura de rejuvenescedores poderia ocasionar no ligante envelhecido que havia sido extraído do material fresado. Pretendia-se verificar se os compostos aromáticos e saturados haviam sido restabelecidos, tomando como parâmetro um CAP novo do tipo 50-70, largamente utilizado em projetos de pavimentação asfáltica na região Centro Oeste do Brasil.

Devido à indisponibilidade de equipamentos nos laboratórios da Universidade de Brasília, optou-se por realizar os ensaios no Centro de Pesquisas e Desenvolvimento Leopoldo Américo Miguez de Mello (CENPES - Petrobrás), com sede na cidade do Rio de Janeiro/RJ. Estes ensaios tiveram seu andamento acompanhado pela equipe técnica do CENPES/Petrobrás. O equipamento utilizado foi o espectrômetro de RMN marca VARIAN, modelo MR-400 e campo magnético de 9,4T (400 MHz em 1H).

\subsection{Caracterização física e reológica dos ligantes}

Após a extração do ligante do material fresado, o CAP envelhecido naturalmente foi também caracterizado com a mesma bateria de ensaios do CAP "virgem" ocorrendo o mesmo com as misturas de CAP rejuvenescido. Esse ensaios foram respectivamente: Penetração, ponto de amolecimento, viscosidade, ductilidade, densidade, variação de massa (RTFOT), ponto de fulgor e combustão.

Os teores de mistura foram definidos em porcentagem em massa do CAP envelhecido, utilizando os agentes rejuvenescedores AR5, AR250, AR500 e RejuvaSeal, nas porcentagens de 15\%, 20\% e $25 \%$ em relação ao peso de ligante de uma mistura de CBUQ convencional com 5\% de ligante.

Posteriormente, todos os materiais como CAP "virgem" (CAP 50/70), CAP envelhecido naturalmente 
(CAPvelho), e os CAP's rejuvenescidos com os teores já mencionados, foram levados à estufa RTFOT nas condições especificadas nas normas, em seguida, foram novamente caracterizados para determinação da variação nas propriedades do material.

Com a finalidade de determinar parâmetros viscoelásticos dos ligantes estudados nesta pesquisa (envelhecido, natural e rejuvenescido), foram realizadas medidas de módulo complexo de cisalhamento $\left(\mathrm{G}^{*}\right)$ e ângulo de fase $(\delta)$ a temperaturas variando entre 46 a $76^{\circ} \mathrm{C}\left(46,52,58,64,70\right.$ e $\left.76^{\circ} \mathrm{C}\right)$ e frequência de carregamentos de $1,59 \mathrm{~Hz}$.

O ensaio consistiu em prensar uma amostra de $25 \mathrm{~mm}$ de diâmetro entre uma placa fixa e outra giratória. Um torque foi aplicado girando a placa de um ponto A para um ponto B, em seguida para um ponto C, enfim retornando para o ponto A.

Conforme recomenda a norma, as amostras foram ensaiadas nas temperaturas correspondentes no prazo máximo de 4 horas. Assim, o equipamento realizou as medições, produzindo os valores de módulo complexo e ângulo de fase automaticamente.

\subsection{Avaliação Ambiental}

A finalidade da caracterização ambiental dos resíduos é verificar a capacidade de lixiviação e de solubilização dos produtos utilizados na recuperação do ligante asfáltico betuminoso, uma vez que, tais produtos ao serem aplicados estarão em contato direto com o meio ambiente e sujeito às intempéries.

Quando a água da chuva entra em contato com substâncias que estão sobre a camada superficial dos solos, carrega consigo substâncias na forma dissolvida (solutos) em direção às regiões mais profundas do solo, geralmente, rumo ao aquífero freático. Esse processo de transporte de solutos (que podem ser nutrientes, poluentes, e outras substâncias dissolvidas) rumo às camadas mais profundas do solo é denominado lixiviação. A abaixo ilustra esse processo.

Os hidrocarbonetos presentes nas misturas asfálticas não sofrem lixiviação com facilidade, mas devese tomar cuidado quando o asfaltos velhos forem aquecido, pois podem liberar hidrocarbonetos que afetam a saúde humana, principalmente daqueles que lidam diretamente com o material [17].

Devido ao fato de os hidrocarbonetos saturados dificilmente sofrerem mudanças com o tempo recomenda se investigar o teor de hidrocarbonetos no betume quando for reciclar o material a quente [17].

Sendo assim, análises de cunho ambiental foram realizadas com o intuito de se avaliar com maior precisão a periculosidade do resíduo, bem como sua mistura com agentes rejuvenescedores com diferentes características estudados nesta pesquisa. A caracterização ambiental das amostras foi realizada seguindo os critérios das normas brasileiras NBR 10004 - Resíduos Sólidos: Classificação[18], NBR 10005 - Lixiviação de Resíduos[19] e NBR 10006 - Solubilização de Resíduos[20] e 10007 - Amostragem de Resíduos[21].

Os ensaios de análise ambiental foram realizados pela AMPRO Laboratório, sediada na cidade de Lorena-SP, tendo como responsável o Engenheiro Químico Marco Antonio Souza Vieira.

Devido ao fato de que este tipo de análise só pode ser feita com resíduos sólidos, não seria possível encaminhar os rejuvenescedores isoladamente para avaliação dos critérios de lixiviação e solubilidade. Assim, optou-se por encaminhar amostras do tipo CBUQ preparadas com material fresado contendo porcentagens de rejuvenescedores iguais às propostas na pesquisa, ou seja, 15, 20 e $25 \%$ em peso do ligante residual presente no fresado utilizado.

Face às dificuldades e custo para a realização dos ensaios ambientais, foram escolhidos apenas três amostras dos materiais utilizados na pesquisa:

- Material Fresado Natural - Material que deu origem à pesquisa e não se tinha um conhecimento sobre os efeitos deste material sobre o meio ambiente;

- Material Fresado + AR-500 - Material a base de óleo de xisto e dentre os ARs utilizados o que apresenta maior concentração de óleos leves, tendo o corpo de prova enviado para a análise um o teor de $25 \%$ de AR 500 sendo esta a situação mais desfavorável;

- Material Fresado + RejuvaSeal - Material a base de alcatrão e também desconhecido o seu impacto sobre o meio ambiente tendo o corpo de prova analisado com teor de $25 \%$ de $\mathrm{Re}$ juvaSeal.

A avaliação ambiental dos materiais servirá como subsídio para a tomada de decisão quanto à destinação final apropriada para o resíduo. 


\section{RESULTADOS E ANÁLISES}

\subsection{Ensaios tradicionais}

O resumo de todos os resultados encontrados nos experimentos realizados está apresentado na Tabela 3 e Tabela 4.

Tabela 3: Resultados experimentais da caracterização física dos ligantes analisados

\begin{tabular}{|c|c|c|c|c|c|c|c|}
\hline Ensaios & Unid. & $\begin{array}{l}\text { Valor de Re- } \\
\text { ferência para } \\
\text { o CAP 50/70 }\end{array}$ & CAP 50/70 & CAP velho & REJ. $15 \%$ & REJ. $20 \%$ & REJ. $25 \%$ \\
\hline $\begin{array}{c}\text { Penetração } \\
\left(100 \mathrm{~g}, 5 \mathrm{~s}, 25^{\circ} \mathrm{C}\right)\end{array}$ & $0,1 \mathrm{~mm}$ & $50-70$ & 53.0 & 40.0 & 130.3 & 169.7 & 171.5 \\
\hline Ponto de amolecimento & ${ }^{\circ} \mathrm{C}$ & 46.0 & 46.5 & 51.0 & 41.8 & 37.3 & 30.0 \\
\hline \multicolumn{8}{|c|}{ Viscosidade Brookfield para Ligantes } \\
\hline a $135^{\circ} \mathrm{C}, \mathrm{sc} 21$ (20rpm) & $\mathrm{cP}$ & 274 & 385 & 545 & 273 & 240 & 168 \\
\hline a $150{ }^{\circ} \mathrm{C}, \mathrm{sc} 21(50 \mathrm{rpm})$ & $\mathrm{cP}$ & 112 & 165 & 256 & 325 & 310 & 305 \\
\hline a $177^{\circ} \mathrm{C}$, sc 21 (100rpm) & $\mathrm{cP}$ & $57-285$ & 60 & 99 & 143 & 135 & 135 \\
\hline $\mathrm{G}^{*} / \operatorname{sen} \delta\left(46^{\circ} \mathrm{C}\right)$ & $\mathrm{kPa}$ & $>1$ & 22 & 51,2 & 11,8 & 7,5 & 4 \\
\hline $\begin{array}{l}\text { Índice de susceptibilida- } \\
\text { de térmica }\end{array}$ & - & $(-1,5)$ a $(+0,7)$ & -2.0 & -1.4 & -1.0 & -2.0 & -6.1 \\
\hline Ponto de combustão & ${ }^{\circ} \mathrm{C}$ & N.A. & 385 & 412 & 220 & 208 & 180 \\
\hline Ponto de fulgor & ${ }^{\circ} \mathrm{C}$ & $>235$ & 325 & 369 & 200 & 194 & 136 \\
\hline Densidade CAP & - & N.A & 1.07 & 1.06 & 1.04 & 1.05 & 1.05 \\
\hline Ductilidade a $25^{\circ} \mathrm{C}$ & $\mathrm{cm}$ & 60 & 100 & 100 & 45 & 43 & 35 \\
\hline \multicolumn{8}{|c|}{ Efeito do calor e do ar (RTFOT) a $163^{\circ} \mathrm{C}, 85 \mathrm{~min}$} \\
\hline Variação em massa & $\%$ massa & $\leq 0,5$ & $0.16 \%$ & $0.09 \%$ & $4.22 \%$ & $5.19 \%$ & $7.01 \%$ \\
\hline $\begin{array}{l}\text { Aumento do ponto de } \\
\text { amolecimento }\end{array}$ & ${ }^{0} \mathrm{C}$ & $\leq 8$ & 1.5 & 2.3 & 15.5 & 19.0 & 26.8 \\
\hline Penetração retida & $\%$ & $\geq 55$ & $73 \%$ & $93 \%$ & $14 \%$ & $10 \%$ & $10 \%$ \\
\hline $\mathrm{G}^{*} / \operatorname{sen} \delta\left(46^{\circ} \mathrm{C}\right)$ & $\mathrm{kPa}$ & $>2$ & 33 & 92,2 & 217,2 & 262 & 269,4 \\
\hline
\end{tabular}


Tabela 4: Resultados experimentais da caracterização física dos ligantes analisados

\begin{tabular}{|c|c|c|c|c|c|c|c|c|c|c|c|}
\hline Ensaios & Unid. & $\begin{array}{l}\text { Valor de Referência } \\
\text { para o CAP 50/70 }\end{array}$ & $\begin{array}{c}\text { AR500 } \\
15 \%\end{array}$ & $\begin{array}{l}\text { AR500 } \\
20 \%\end{array}$ & $\begin{array}{c}\text { AR500 } \\
25 \%\end{array}$ & $\begin{array}{c}\text { AR250 } \\
15 \%\end{array}$ & $\begin{array}{l}\text { AR250 } \\
20 \%\end{array}$ & $\begin{array}{c}\text { AR250 } \\
25 \%\end{array}$ & $\begin{array}{l}\text { AR5 } \\
15 \%\end{array}$ & $\begin{array}{l}\text { AR5 } \\
20 \%\end{array}$ & $\begin{array}{l}\text { AR5 } \\
25 \%\end{array}$ \\
\hline $\begin{array}{c}\text { Penetração } \\
\left(100 \mathrm{~g}, 5 \mathrm{~s}, 25^{\circ} \mathrm{C}\right)\end{array}$ & $0,1 \mathrm{~mm}$ & $50-70$ & 39.8 & 43.5 & 44.3 & 44.3 & 46.0 & 49.8 & 65,6 & 68,3 & 88,5 \\
\hline $\begin{array}{l}\text { Ponto de amo- } \\
\text { lecimento }\end{array}$ & ${ }^{\circ} \mathrm{C}$ & 46.0 & 49.3 & 50.0 & 49.8 & 49.0 & 47.5 & 47.8 & 47,7 & 47,2 & 46,1 \\
\hline \multicolumn{12}{|c|}{ Viscosidade Brookfield para Ligantes } \\
\hline $\begin{array}{c}\text { a } 135^{\circ} \mathrm{C}, \mathrm{sc} 21 \\
(20 \mathrm{rpm})\end{array}$ & $\mathrm{cP}$ & 274 & 535 & 500 & 490 & 478 & 455 & 428 & 335 & 285 & 250 \\
\hline $\begin{array}{c}150^{\circ} \mathrm{C}, \mathrm{sc} 21 \\
(50 \mathrm{rpm})\end{array}$ & $\mathrm{cP}$ & 112 & 280 & 265 & 263 & 258 & 243 & 233 & 183 & 155 & 135 \\
\hline $\begin{array}{l}\text { a } 177^{\circ} \mathrm{C}, \text { sc } 21 \\
\text { (100rpm) }\end{array}$ & $\mathrm{cP}$ & $57-285$ & 123 & 115 & 80 & 113 & 110 & 105 & 85 & 75 & 65 \\
\hline $\mathrm{G}^{*} / \operatorname{sen} \delta\left(46^{\circ} \mathrm{C}\right)$ & $\mathrm{kPa}$ & $>1$ & 42,3 & 40,3 & 43,7 & 32,6 & 32 & 32,8 & 15,4 & 12 & 8,2 \\
\hline $\begin{array}{l}\text { Índice de sus- } \\
\text { ceptibilidade } \\
\text { térmica }\end{array}$ & - & $(-1,5)$ a $(+0,7)$ & -1.9 & -1.5 & -1.5 & -1.7 & -2.0 & -1.8 & $-1,2$ & $-1,2$ & $-0,8$ \\
\hline $\begin{array}{l}\text { Ponto de com- } \\
\text { bustão }\end{array}$ & ${ }^{\circ} \mathrm{C}$ & N.A. & 336 & 340 & 338 & 342 & 342 & 340 & 340 & 334 & 322 \\
\hline Ponto de fulgor & ${ }^{\circ} \mathrm{C}$ & $>235$ & 308 & 318 & 310 & 322 & 328 & 320 & 304 & 306 & 298 \\
\hline Densidade CAP & - & N.A & 1.01 & 1.02 & 1.03 & 1.03 & 1.02 & 1.02 & 1.02 & 1.02 & 1.02 \\
\hline $\begin{array}{l}\text { Ductilidade a } \\
25^{\circ} \mathrm{C}\end{array}$ & $\mathrm{cm}$ & 60 & 100 & 100 & 100 & 100 & 100 & 100 & 100 & 88.2 & 100 \\
\hline \multicolumn{12}{|c|}{ Efeito do calor e do ar (RTFOT) a $163^{\circ} \mathrm{C}, 85 \mathrm{~min}$} \\
\hline $\begin{array}{l}\text { Variação em } \\
\text { massa }\end{array}$ & $\begin{array}{c}\% \\
\text { massa }\end{array}$ & $\leq 0,5$ & 0.17 & 0.54 & 0.45 & 0.46 & 0.42 & 0.53 & 0.23 & 0.24 & 0.27 \\
\hline $\begin{array}{l}\text { Aumento do } \\
\text { ponto de amo- } \\
\text { lecimento }\end{array}$ & ${ }^{0} \mathrm{C}$ & $\leq 8$ & 4.8 & 3.3 & 3.0 & 4.0 & 5.0 & 2.5 & 2.0 & 2.8 & 0.9 \\
\hline $\begin{array}{l}\text { Penetração } \\
\text { retida }\end{array}$ & $\%$ & $\geq 55$ & $54 \%$ & $49 \%$ & $49 \%$ & $45 \%$ & $46 \%$ & $49 \%$ & $78 \%$ & $83 \%$ & $69 \%$ \\
\hline $\mathrm{G}^{*} / \operatorname{sen} \delta\left(46^{\circ} \mathrm{C}\right)$ & $\mathrm{kPa}$ & $>2$ & 133,4 & 136 & 134,6 & 109 & 114,8 & 111,6 & 53,3 & 49,3 & 47,2 \\
\hline
\end{tabular}

É possível observar que a adição dos rejuvenescedores favoreceu a diminuição da consistência do ligante envelhecido, conferindo maiores valores de penetração. O RejuvaSeal proporcionou à mistura uma penetração muito elevada nos três teores aplicados que inviabiliza o uso do material nestas porcentagens.

Além disso, observa-se que todos os rejuvenescedores utilizados pela pesquisa proporcionaram aumento na penetração, mas quando submetido ao envelhecimento em curto prazo a penetração diminuiu con- 
sideravelmente com exceção da mistura utilizando AR5 principalmente no teor de 20\% após o RTFOT, indicando que para esta característica este é o material que melhor se aproxima do valor da penetração do CAP "virgem" (CAP 50/70).

Dentre as configurações de ligantes rejuvenescidos, a que apresenta maior risco de se inflamar é a que contém RejuvaSeal, principalmente na taxa de $25 \%$, as demais configurações, utilizando AR-5, AR-250 ou AR-500 para qualquer porcentagem de mistura, apresentaram valores superiores aos indicados para um CAP do tipo 50/70, sendo, portanto, recomendados para utilização em campo.

É possível observar que após a mistura de agente rejuvenescedor ao CAPvelho não se verificou mudança significativa no valor da densidade do material, apesar de os rejuvenescedores isoladamente apresentarem valores de densidade inferiores. Assim, nota-se que este fato se deu principalmente devido aos teores ARs ou RejuvaSeal não serem suficientemente expressivos ao ponto de alterar esta característica do ligante.

O RejuvaSeal nas três porcentagens analisadas teve uma alta perda de massa indicando um alto índice de volatilidade e uma grande capacidade de perda das frações leves, uma vez que apresentava aspecto oleoso e mais fluido que os demais rejuvenescedores estudados nesta pesquisa.

Com exceção da configuração CAPvelho+20\% AR-500, cuja perda de massa foi de 0,54\%, os demais rejuvenescedores tiveram comportamento parecido entre si, tendo a sua variação da perda de massa da ordem de $0,23 \%$ a $0,54 \%$ o que caracteriza um bom comportamento quando comparados ao limite máximo de $0,5 \%$ para um CAP 50/70.

Verifica-se ainda, que a maior variação de viscosidade ocorreu no material com adição de RejuvaSeal. Antes do RTFOT ele apresentava a menor viscosidade dentre todos os materiais e após o envelhecimento apresentou a maior viscosidade, este aumento de viscosidade se deve a perda de frações leves e oxidação do material quando este é submetido à temperatura mais elevadas provocando o endurecimento do material $\mathrm{e}$ conseguinte aumento de sua viscosidade, comprovado pelo ensaio de perda de massa (RTFOT). Isso portanto, é um indicativo de que o RejuvaSeal não é um material adequado para aplicação em rejuvenescimento, pois estar susceptível demais à variação de temperatura e do ar (RTFOT) o faz um material frágil e com baixa vida útil.

\subsection{Reologia dos ligantes asfálticos}

O ensaio de cisalhamento dinâmico foi realizado para todos os ligantes analisados nesta pesquisa, ressaltando o interesse em determinação do parâmetro indicativo da deformação permanente que é governada pelo valor de $\mathrm{G}^{*} / \operatorname{sen} \delta$.

Segundo a especificação SUPERPAVE, os valores de G*/sen $\delta$ devem ser maiores que $1,0 \mathrm{kPa}$ para o ligante em estado natural e superior a 2,0 kPa para o ligante que tenha sido submetido ao envelhecimento em curto prazo (RTFOT), sendo as amostras com altos valores de $\mathrm{G}^{*}$ e baixos valores de $\delta$ menos sujeitas a problemas de deformações permanentes de caráter viscoso. Os valores mínimos especificados foram alcançados para todos os ligantes avaliados para a temperatura de até $70^{\circ} \mathrm{C}$, ou seja, para temperaturas maiores que $70^{\circ} \mathrm{C}$, esses ligantes não seriam indicados.

O ligante que mais sofreu alteração nesta característica foi o ligante com adição de RejuvaSeal, que em todas as porcentagens passou de uma condição de menor rigidez (antes RTFOT) para a maior rigidez após ser submetido ao envelhecimento em curto prazo.

Também foram avaliados resultados de ângulo de fase $(\delta)$, apresentados na Tabela 5.

Tabela 5: Resultados dos ângulos de fase obtidos para os ligantes.

\begin{tabular}{ccccccc}
\hline \multirow{2}{*}{ Material } & \multicolumn{2}{c}{$\mathbf{1 5 \%}$} & \multicolumn{2}{c}{$\mathbf{2 0 \%}$} & \multicolumn{2}{c}{$\mathbf{2 5 \%}$} \\
& Antes & Após & Antes & Após & Antes & Após \\
& RTFOT & RTFOT & RTFOT & RTFOT & RTFOT & RTFOT \\
\hline CAP velho & 84,71 & 82,0 & 84,71 & 82,0 & 84,71 & 82,0 \\
CAP velho +RejuvaSeal & 83,08 & 67,27 & 83,34 & 65,14 & 84,2 & 65,6 \\
CAP velho +AR-5 & 81,51 & 76,54 & 81,85 & 78,09 & 83,36 & 76,83 \\
CAP velho +AR-250 & 80,2 & 73,61 & 80,65 & 73,75 & 81,44 & 73,89 \\
CAP velho +AR-500 & 77,88 & 71,65 & 77,62 & 71,88 & 77,67 & 71,7 \\
CAP 50/70 & 79,1 & 77,3 & 79,1 & 77,3 & 79,1 & 77,3 \\
\hline
\end{tabular}

Quando avaliados os resultados aqui apresentados e comparando com os resultados de viscosidade, é possível observar que os valores de ângulo de fase ( $(\delta)$ são inversamente proporcionais à viscosidade dos ligantes avaliados. Isto significa que ligantes mais viscosos apresentam melhor resistência à formação de trin- 
cas por fadiga no pavimento. Além disso, após o ensaio de RTFOT houve uma inversão dos valores de ângulo de fase, ou seja, aqueles ligantes cuja viscosidade era mais baixa perderam frações leves, tornando o material mais consistente e, portanto mais viscoso, reduzindo então seu valor de ângulo de fase. Um bom exemplo deste fato é o ligante com adição de RejuvaSeal, que em todas as configurações passou de uma condição cujo ângulo de fase era o menor entre os demais, para a condição com maior valor de $\delta$.

\subsection{Análise química dos ligantes asfálticos}

Além da caracterização física e reológica, foram avaliados quais rejuvenescedores e quantidades fizeram com que o ligante extraído (envelhecido) apresentasse compostos químicos em quantidade semelhante à de um CAP 50/70.

\subsubsection{Composição SARA}

A cromatografia sobre coluna de sílica IATROSCAN permitiu separar diretamente os constituintes dos ligantes asfálticos avaliados nesta pesquisa. Foram obtidas as quatro famílias SARA em função da polaridade do ligante, onde a partir do teor de cada fração foi possível verificar qual a quantidade e o rejuvenescedor fez com que o ligante envelhecido se aproximasse de um CAP 50/70 tomado como padrão.

A Tabela 6 traz os resultados obtidos para cada configuração estudada. Nela é possível observar os resultados obtidos para cada fração SARA em todas as configurações avaliadas, comparando-as inicialmente com os valores típicos estabelecidos pelo manual da Shell [22], onde a composição de Saturados deve estar entre 5 a 20\%; Aromáticos (40 a 65\%); Resinas (\% gelatina); Asfaltenos (5 a 25\%) e também com os valores obtidos para o CAP 50/70.

Tabela 6: Composição química dos ligantes avaliados pelo método SARA

\begin{tabular}{l|c|c|c|c|c}
\hline \multicolumn{1}{c|}{ LIGANTES AVALIADOS } & $\begin{array}{c}\text { SATURADOS } \\
\text { (5 A 20\%) }\end{array}$ & $\begin{array}{c}\text { AROMÁTICOS } \\
\text { (40 A 65\%) }\end{array}$ & $\begin{array}{c}\text { RESINAS \% } \\
\text { (GELATINA) }\end{array}$ & $\begin{array}{c}\text { ASFALTENOS } \\
\text { (5 A 25\%) }\end{array}$ & $\begin{array}{c}\text { ÍNDICE DE } \\
\text { INSTABILIDADE } \\
\text { COLOIDAL (IC) }\end{array}$ \\
\hline CAP 50/70 & 7,9 & 44 & 33 & 16 & 0,31 \\
\hline CAP velho & 8,8 & 34 & 36 & 22 & 0,44 \\
\hline CAPvelho+ 15\% AR 5 & 7,5 & 37 & 33 & 22 & 0,42 \\
\hline CAPvelho+ 20\% AR 5 & 8,3 & 40 & 35 & 17 & 0,34 \\
\hline CAPvelho+ 25\% AR 5 & 7,6 & 44 & 32 & 16 & 0,31 \\
\hline CAPvelho+ 15\% AR 250 & 7,5 & 37 & 33 & 22 & 0,42 \\
\hline CAPvelho + 20\% AR 250 & 8,4 & 39 & 34 & 18 & 0,36 \\
\hline CAPvelho+ 25\% AR 250 & 7,5 & 30 & 42 & 20 & 0,38 \\
\hline CAPvelho+ 15\% AR500 & 6,8 & 34 & 35 & 24 & 0,45 \\
\hline CAPvelho+ 20\% AR 500 & 7,2 & 34 & 35 & 24 & 0,45 \\
\hline CAPvelho + 25\% AR 500 & 8,2 & 29 & 41 & 21 & 0,42 \\
\hline CAPvelho + 15\% RejuvaSeal & 4,7 & 33 & 39 & 23 & 0,38 \\
\hline CAPvelho + 20\% RejuvaSeal & 6,3 & 34 & 35 & 24 & 0,44 \\
\hline CAPvelho + 25\% RejuvaSeal & 6,5 & 36 & 35 & 22 & 0,40 \\
\hline
\end{tabular}

É possível observar que o teor de asfaltenos não apresentou variação fora dos limites estabelecidos pela Shell [22]. Entretanto, os teores de saturados e aromáticos por vezes apresentaram valores incompatíveis com aqueles tomados como padrão.

Nota-se pela Tabela 3, que as únicas composições que se enquadraram nos padrões estabelecidos foram, respectivamente, o CAP+20\% de AR5 e CAP+25\% de AR5, recompondo principalmente a fração de aromáticos e redução das resinas e asfaltenos, produzindo uma ligante semelhante ao CAP 50/70.

Estes compostos aromáticos sofrem com a ação da temperatura e exposição ao ar, fazendo com que sejam condensados (reduzidos), produzindo resinas e parte das resinas produz asfaltenos, formando assim uma mistura bastante instável [23].

O Índice de Instabilidade Coloidal (Ic) de todos os ligantes avaliados pode ser enquadrado numa condição intermediária $(0,1 \leq \mathrm{Ic} \leq 0,5)$, onde quanto maior for Ic, maior será a Instabilidade Coloidal do asfalto e mais difícil a incorporação de um modificador, como por exemplo, um polímero[24]. Entretanto, é possível 
notar que os ligantes CAP+20\% de AR5 e CAP+25\% de AR5, cujos compostos aromáticos enquadraram-se nas especificações da Shell [22], foram os que tiveram melhor Ic, ou seja, possuem os menores valores e, portanto, podem ser considerados os mais estáveis.

Apesar de comprovada eficiência dos produtos, foi ainda verificada a eficácia de tais incorporações de rejuvenescedores no ligante envelhecido, de modo a verificar qual se aproximava mais de um CAP 50/70. Para tal, foi realizada Análise de Variância (ANOVA) onde pares de ligantes foram combinados, na expectativa de verificação do nível de significância, ou seja, o quanto os resultados de um ligante se aproximava de outro.

O resumo dos resultados é apresentado na Tabela 7, em forma de matriz, informando o nível observado de significância "p", obtido na análise para cada um dos pares encontrados.

Tabela 7: Níveis de Significância (p\%) de valores de cromatografia - método SARA.

\begin{tabular}{|c|c|c|c|}
\hline Ligantes & CAP 50/70 & CAPvelho+20\% AR5 & CAPvelho+25\% AR5 \\
\hline CAP 50/70 & & & \\
\hline CAPvelho+20\% AR5 & $98,81 \%$ & & \\
\hline CAPvelho+25\% AR5 & $98,96 \%$ & $97,84 \%$ & \\
\hline
\end{tabular}

O cruzamento do ligante CAP 50/70 com o CAPvelho+25\% AR5 indica a maior probabilidade de as frações SARA serem fisicamente iguais. Por outro lado, observa-se que o cruzamento do ligante das frações SARA do ligante CAPvelho+20\% de AR5 com o CAPvelho+25\% de AR5 apresenta uma probabilidade de $97,84 \%$ de semelhança entre estes. Isto pode ser explicado devido ao fato de que estes ligantes foram modificados com o mesmo rejuvenescedor em porcentagens muito próximas, o que lhes conferiu tamanha semelhança.

A escolha entre um e outro ligante rejuvenescido certamente deverá basear-se numa questão econômica e não técnica, pois qualquer um dos dois materiais conseguiu recuperar as frações leves perdidas durante o processo de envelhecimento ao qual o ligante esteve exposto durante as fases de mistura, transporte, espalhamento, compactação e vida de serviço.

\subsubsection{Espectros -RMN}

Os espectros de RMN 1H e RMN 13C fundamentaram a observação de qual ligante mais se aproximava de um ligante virgem, que para esta pesquisa foi o CAP 50/70. Observou-se que todas as configurações avaliadas apresentavam valores dos grupos Saturados e Aromáticos semelhantes aos de um CAP 50/70 tomado como padrão de referência. Entretanto, foram realizadas Análises de Variâncias (ANOVA) combinando pares de ligantes, onde se pretende verificar o nível de significância, ou seja, o quanto os resultados de um ligante rejuvenescido se aproximava do CAP 50/70, comparando estes grupos de compostos Aromáticos e Saturados.

O resumo dos resultados é apresentado na Tabela 8 em forma de matriz, informando o nível observado de significância "p", obtido na análise para cada um dos pares encontrados

Tabela 8: Níveis de Significância (p\%) de valores de cromatografia - método RMN.

\begin{tabular}{l|c|l|c}
\hline \multicolumn{1}{c|}{ Ligantes avaliados } & CAP 50/70 & \multicolumn{1}{c|}{ Ligantes avaliados } & CAP 50/70 \\
\hline CAPvelho + 15\% AR 5 & $99,71 \%$ & CAPvelho + 15\% AR500 & $98,80 \%$ \\
\hline CAPvelho + 20\% AR 5 & $99,80 \%$ & CAPvelho + 20\% AR 500 & $98,80 \%$ \\
\hline CAPvelho + 25\% AR 5 & $99,50 \%$ & CAPvelho + 25\% AR 500 & $98,76 \%$ \\
\hline CAPvelho + 15\% AR 250 & $99,00 \%$ & CAPvelho + 15\% RejuvaSeal & $97,90 \%$ \\
\hline CAPvelho + 20\% AR 250 & $99,40 \%$ & CAPvelho + 20\% RejuvaSeal & $96,90 \%$ \\
\hline CAPvelho + 25\% AR 250 & $99,95 \%$ & CAPvelho + 25\% RejuvaSeal & $94,30 \%$ \\
\hline
\end{tabular}

Quando comparados, todos os ligantes se aproximaram do CAP 50/70, sendo as seguintes as três melhores combinações em ordem decrescente de probabilidade: CAPvelho+25\% AR250 (p=99,95\%), CAPvelho+20\% AR5 ( $\mathrm{p}=99,8 \%$ ) e por fim o CAPvelho+15\% AR5 ( $\mathrm{p}=99,71 \%)$.Entretanto, a escolha entre um dos três ligantes deverá ser baseada naquele que apresentou componentes da fração SARA compatíveis com o CAP 50/70, ou seja, CAPvelho+20\% AR5, uma vez que o ensaio de RMN só separa grupos de compostos 
aromáticos e saturados.

\subsection{Avaliação do potencial agressor ao meio ambiente}

Os ensaios de periculosidade realizados foram os testes de lixiviação, solubilização, análise de massa, inflamabilidade, corrosividade e reatividade. Todos realizados conforme metodologia preconizada nas Normalizações Brasileiras.

A norma brasileira que classifica os resíduos industriais é a NBR-10.004:2004 da ABNT. Esta norma classifica os Resíduos em 2 (duas) classes, quais sejam: Classe I - resíduo perigoso, Classe II - resíduos não perigosos, sendo esta última subdivida em: Classe II A - Não Inertes e Classe II B - Inertes.

Mediante os boletins de análise, contendo resultados das amostras analisadas os três resíduos em questão (Fresado, Fresado + AR 500, Fresado + Rejuvaseal) foram classificados como sendo de Classe II A Não Perigoso e Não Inerte, visto que o mesmo não se enquadra nas classificações de resíduos classe I - Perigosos ou de resíduos classe II-B - Inertes nos termos da norma ABNT NBR 1004:2004. Os resultados apresentados pela empresa executora não comentaram quantitativamente os resultados, mas apenas qualitativamente. Logo o resíduo isolado ou com mistura de quaisquer dos rejuvenescedores avaliados nesta pesquisa, poderá ser encaminhado para aterros sanitários de resíduos classe II-A, ou mesmo utilizado em projetos de Pavimentação sem restrições quanto a aplicação como um Concreto Betuminoso Usinado a Quente (CBUQ).

\section{CONCLUSÃO}

O ligante asfáltico extraído do material fresado realmente estava envelhecido, uma vez que este material não teve substancial mudança em suas características de penetração, ponto de amolecimento, viscosidade e perda de massa após o envelhecimento RTFOT.

Observa-se que todas as porcentagens de incorporações de agentes rejuvenescedores ao CAP envelhecido favorecem a diminuição da consistência do ligante envelhecido, conferindo maiores valores de penetração, redução do ponto de amolecimento e, sensível redução do ponto de fulgor e o ponto de combustão, exceto para misturas com RejuvaSeal.

Os ensaios realizados pela metodologia SUPERPAVE indicaram que a perda de massa pelo método RTFOT indicou que os valores permaneceram dentro dos limites estabelecidos, exceto par mistura com RejuvaSeal.

A maior variação de viscosidade ocorreu no material com adição de RejuvaSeal, que antes do RTFOT apresentava a menor viscosidade dentre todos os materiais e após envelhecimento apresentou a maior viscosidade. Isto se deve ao fato que este material teve a maior perda de frações leves. O material cuja viscosidade melhor se aproximava do comportamento de um CAP 50/70 foi o agente rejuvenescedor AR-5 em todas as porcentagens de adição;

Todos os ligantes apresentaram valores obtidos de $\mathrm{G}^{*} / \operatorname{sen} \delta$ compatíveis com a especificação SUPERPAVE. Estes resultados também indicaram que os ligantes com menor viscosidade (mais consistentes) apresentaram os maiores valores de rigidez $\left(\mathrm{G}^{*} / \mathrm{sen} \delta\right)$, ou seja, são mais resistentes ao acúmulo de deformação permanente.

A avaliação química realizada por meio da cromatografia IATROSCAN permitiu separar e quantificar as quatro famílias SARA, onde foi possível verificar qual a quantidade e o rejuvenescedor que levou o ligante envelhecido a comportar-se mais próximo de um CAP 50/70, tomado como padrão de obras rodoviárias, principalmente em âmbito federal.

As composições que melhor se enquadraram nos padrões estabelecidos pela Shell [21] foram, respectivamente, a composição com adição de $20 \%$ e $25 \%$ de AR-5, as quais recompuseram principalmente a fração de aromáticos com redução das resinas e asfaltenos, produzindo um ligante com frações SARA semelhantes ao CAP 50/70. Estes mesmos ligantes foram os que tiveram o melhor Índice de Instabilidade Coloidal (Ic), ou seja, possuem os menores valores sendo, portanto, considerados os mais estáveis dentre todas as configurações avaliadas.

Os espectros de RMN indicaram a adição de $25 \%$ de AR-250 como a melhor opção para restabelecer as características químicas do ligante envelhecido, seguido da configuração com $15 \%$ e $20 \%$ de AR-5. Entretanto, como esta análise considera somente grupos de compostos aromáticos e saturados, a escolha do ligante em função da característica química deve ser realizada com base na cromatografia IATROSCAN, capaz de identificar todas as famílias SARA, ou seja, o melhor material seria aquele com a adição de 20\% de AR-5. 
Com relação às análise de lixiviação e solubilidade, chamados ensaios de periculosidade, foi possível observar que as misturas asfálticas contento ou não os rejuvenescedores estudados nesta pesquisa, não apresentam riscos quanto a contaminação do meio ambiente podendo os mesmos ser utilizados em obras rodoviárias, ou caso necessário, depositados em aterros sanitários quando não reaproveitados.

\section{AGRADECIMENTOS}

Os autores agradecem a Universidade de Brasília e ao CNPq, pela oportunidade a aporte tecnológico para desenvolvimento desta pesquisa.

\section{BIBLIOGRAFIA}

[1] IBGE. Estimativas populacionais para os municípios e para as Unidades da Federação brasileiros em 01.07.2017. Disponível em www.ibge.gov.br. Acesso em 01 outubro de 2017.

[2] CNT. Pesquisa rodoviária 2016: relatório gerencial. In: Confederação Nacional do Transporte, Brasília, 2016.

[3] SILVA, J.P.S. Avaliação dos efeitos de produtos rejuvenescedores em misturas asfálticas, Tese de D.Sc., Programa de Pós-graduação em Geotecnia, Universidade de Brasília. 2011.

[4] BONFIM, V., DOMINGUES, F. A. A. "Utilização de Fresagem e Reciclagem "In Situ” a Frio. Alternativas na Recuperação de Pavimentos Asfálticos”, In: 29a Reunião Anual de Pavimentação, Volume 3, Cuiabá, MT, 1995

[5] TUCHUMANTEL, J. O. “Avaliação Estrutural de Trecho Experimental Urbano de Pavimento Asfáltico Reciclado a Frio”, In: 35ª Reunião Anual de Pavimentação, Rio De Janeiro- RJ - Brasil. 2004.

[6] DNC. Portaria DNC n44. Departamento Nacional de Combustíveis, 1997.

[7] LIMA, A.T. Caracterização Mecânica de Misturas Asfálticas Recicladas a Quente. Dissertação de M.Sc., Programa de Mestrado em Engenharia de em Engenharia de Transportes, Centro de Tecnologia, Universidade Federal do Ceará, Fortaleza, 2003.

[8] FWA, T. F. Evaluation of Engineering Benefits of RJSeal Report preparated for Kalvani International Pte Ltd. Departmet of Civil Engineering. National University of Singapore, 2006.

[9] REJUVASEAL. Composition of'Rejuvaseal”. Technical Data. Disponível em www.rejuvaseal.com.hk. Acesso em fevereiro de 2010.

[10] MAH, V. Concept of P4 - Perpetual Pavement Presentation Process. PRI- Pavement Rejuvenation International. Disponível em www.rejuvaseal.com. Acesso em Março de 2008.

[11] SILVA, J.P.S., FARIAS, M. M., JIMÉNEZ, A. M. G. "Avaliação do Efeito Selante de Agente Rejuvenescedor em Misturas Asfálticas”, In: $20^{\circ}$ Encontro de Asfalto, IBP Instituto Brasileiro de Petróleo, Gás e Biocombustíveis, Rio de Janeiro, Brasil. Maio de 2010.

[12] ASTM D 4402. Standard Practice for Recovery of Asphalt from Solution Using the Rotary Evaporator. American Society for Testing and Materials. 1995.

[13] CORBETT, L.W. "Composition of asphalt based on generic fractionation using solvent deasphalting, elution - adsorption chromatography and densimetric characterization”, An. Chem., v.41, p.576-579, 1969.

[14] GAESTEL, C., SHADJA, R., LAMMINAN K.A.. "Contribution à la connaissance des proprietés dês bitumes routiers", Bull. Laboratoire des Ponts e Chausées, v.466, p.85-97.1971.

[15] SHAKIRULlAH, M., AHMAD, I., RAHMAN, H., et al., "Spectral Analysis of Some Distillates From Asphalt Cracking and Evaluation of UTIMAC as Cracking Catalyst", Journal of the Chinese Chemical Society, v. 53, 2006.

[16] JENNINGS, P. W., PRIBANIC, J. A. Binder Characterization and Evaluation by Nuclear Magnetic Resonance Spectroscopy. Final Report Strategic Highway Research Program SHRP-A-335, p. 150, 1991.

[17] HENDRIKS, C.F., NIJKERK, A.A., VANKOPPEN, A.E. O ciclo da construção. Tradução, Brasília, Editora Universidade de Brasília. 2007. 
[18] NBR 10.004. Resíduos Sólidos - Classificação. NBR. Associação Brasileira de Normas Técnicas, a. Rio de Janeiro. 1987.

[19] NBR 10.005. Lixiviação de Resíduos. NBR. Associação Brasileira de Normas Técnicas, b. Rio de Janeiro. 1987.

[20] NBR 10.006. Solubilização de Resíduos. NBR. Associação Brasileira de Normas Técnicas, c. Rio de Janeiro. 1987.

[21] NBR 10.007. Amostragem de resíduos. NBR. Associação Brasileira de Normas Técnicas, c. Rio de Janeiro. 1987.

[22] SHELL. SHELL Bitumen Handbook. SHELL, Inglaterra.2003.

[23] SILVA, L. S. Contribuição ao estudo do envelhecimento de ligantes asfálticos. Influência na adição de polímeros e comportamento frente a radiação UV. Tese de D.Sc., UFRGS, Porto Alegre, 2005.

[24] GLITA S. Contribuition à l'étude physico-chimie dês bitumes. Havre. Thèse Doctorat, Faculté des Sciences et Techniques de l'Université du Havre.1988. 